\title{
Inappropriate ICD Discharge Related to Electrical Muscle Stimulation in Chiropractic Therapy: A Case Report
}

\author{
Abhishek Shenoy $\cdot$ Abhishek Sharma $\cdot$ Firehiwot Achamyeleh
}

Received: October 11, 2016/ Published online: March 3, 2017

(C) The Author(s) 2017. This article is published with open access at Springerlink.com

\begin{abstract}
Implantable cardioverter defibrillators (ICDs) have been shown to reduce mortality in highrisk patients. Despite several advances in programming ICDs, inappropriate shocks persist and continue to be psychologically and physically disturbing. External electromagnetic interference from electrocautery, welding, acupunctures, low-output transcutaneous electric nerve stimulators, and electronic muscle stimulators may result in inappropriate ICD sensing and shock. We present a 63-year-old female who presented to the emergency department after an ICD shock while undergoing electronic muscle stimulation in
\end{abstract}

Enhanced content To view enhanced content for this article go to http://www.medengine.com/Redeem/ BF87F0607133DAE7.

A. Shenoy

College of Medicine, SUNY Downstate Medical

Center, Brooklyn, USA

\section{A. Sharma $(\bowtie)$}

Department of Cardiovascular Medicine, SUNY

Downstate Medical Center, Brooklyn, NY, USA

e-mail: abhisheksharma4mamc@gmail.com

\section{A. Sharma}

Institute of Cardiovascular Science and Technology,

Brooklyn, NY, USA

F. Achamyeleh

Department of Medicine, SUNY Downstate Medical

Center, Brooklyn, USA chiropractic treatment, during which light electrical pulses were sent through skin electrodes. Our case highlights the importance of recognizing methods used by alternative medicine doctors, including electrical muscle stimulation that may cause electromagnetic interference and inappropriate ICD discharge and therefore, a higher overall mortality risk.

Keywords: Electromagnetic

interference; Implantable cardioverter defibrillator;

\section{INTRODUCTION}

Implantable cardioverter defibrillators (ICDs) have been shown to reduce mortality in highrisk patients. Despite several advances in programming ICDs, inappropriate shocks persist and continue to be psychologically disturbing and arrhythmogenic. Inappropriate discharges can be due to device malfunction such as sensing lead failure, insulation failure, and loose lead connections at the ICD header or adopters. External electrical interference from electrocautery, welding, acupunctures, low-output transcutaneous electric nerve stimulators (TENS) and electronic muscle stimulators (EMS) may result in appropriate ICD sensing and shock therapy [1-4]. We present a 63-year-old female who presented to the emergency 
department after an ICD shock while undergoing electronic muscle stimulation in chiropractic treatment,

\section{CASE REPORT}

A 63-year-old female with a past medical history significant for hypertension, atrial fibrillation $\mathrm{s} / \mathrm{p}$ ablation, hypertrophic cardiomyopathy $\mathrm{s} / \mathrm{p}$ ICD placement, heart failure with an ejection fraction of $40 \%$, left atrial appendage thrombus presented to the emergency department after an ICD shock while undergoing electronic muscle stimulation in chiropractic treatment. The patient's medication list includes dabigatran, lisinopril, and metoprolol. The ICD shock was aborted upon ceasing the chiropractic manipulation. Upon arrival to the emergency department, her blood pressure was 146/98, heart rate 106 , respiratory rate 19 , and oxygen saturation of $100 \%$ on room air. The patient's dual-chamber ICD with Durata, Biphasic waveform defibrillator leads was interrogated in the emergency room, which revealed that it was in DDDR mode with an A lead impedance of $460 \mathrm{Ohms}$, and a $\mathrm{V}$ lead impedance of 430 Ohms. The max track rate was set at 130 and paced AV delay was at 150 . Detection criteria were 153 beats per minute (bpm) for VT-1 (monitor only), $200 \mathrm{bpm}$ for VT-2, and $240 \mathrm{bpm}$ for VF (ATP $3 \times, 550 \mathrm{~V}$, $845 \mathrm{~V}, 890 \mathrm{~V} 2 \times$ for both VT-2 and VF). It further showed intermittent low-amplitude sinusoidal wave interference or noise from the chiropractic muscle stimulation, which resulted in false sensing by the ICD (Fig. 1), which eventually lead to a shock (Fig. 2). The patient converted to sinus rhythm after the shock (Fig. 3). Physical exam was unremarkable and EKG revealed a paced rhythm with pre-atrial contractions. The patient's hospital course was uneventful; she had two sets of negative troponin I, and eventually discharged home with the advice to avoid TENS therapy.

In chiropractic therapy, low-output TENS is transmitted to relieve pain and/or spasm of the particular muscle or muscle group. Common side effects experienced by the patient in this setting include pins-and-needles sensation, muscle twitching, or even full muscle contraction, which may last up to $30 \mathrm{~min}$. To differentiate between skeletal muscle over-sensing (pectoral myopotentials) versus inappropriate discharge relating to electromagnetic interference (EMI), a thorough analysis of the lead strips was performed. We believe external electromagnetic interference is the cause in our case as there is a patient history consistent with an encounter with an EMI source (TENS). In addition, there is noise seen in all sensing channels (Fig. 1), a finding consistent with EMI. In Fig. 3, once the EMI had resolved and there was discontinuation of TENS, noise is absent. On the other hand, skeletal muscle over-sensing (pectoral myopotentials) usually only occurs when there is provocative skeletal isometric exercise involving the upper extremities/abdominal muscles, a scenario not surrounding our patient.

\section{COMPLIANCE WITH ETHICS GUIDELINES}

Informed consent was obtained from the patient for being included in the study.

\section{DISCUSSION}

Electromagnetic interference associated with EMS and TENS can lead to an inappropriate shock from ICD. Although ICDs are programmed to work around certain electrical devices and prevent any harm to the patient, stimulation of musculature by direct application of electric current could lead to electrical signals, which might be misinterpreted by ICD. Accordingly, patients with ICDs and pacemakers are generally advised to avoid such therapies.

Studies have reported that ICD discharges, in general, are associated with an increase in cardiovascular mortality and that ICDs should be delivering the least amount of discharge necessary to protect patients from malignant ventricular arrhythmias such as ventricular tachycardia and ventricular fibrillation $[5,6]$. Further, inappropriate ICD firing has been 


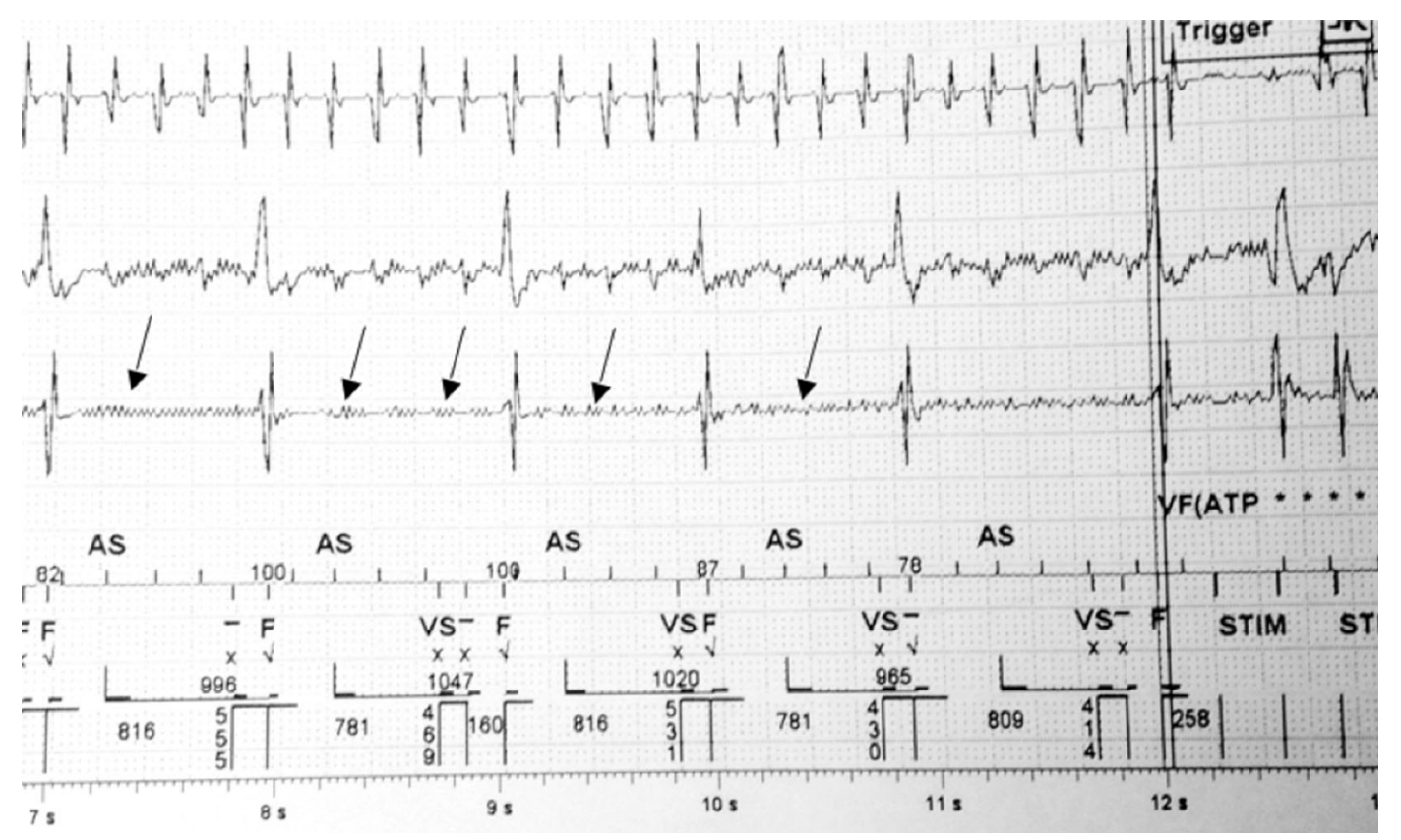

Fig. 1 Interrogation strip demonstrating electrical interference from the low-intensity electronic muscle stimulation. The device senses the interference and attempts anti-tachycardia pacing

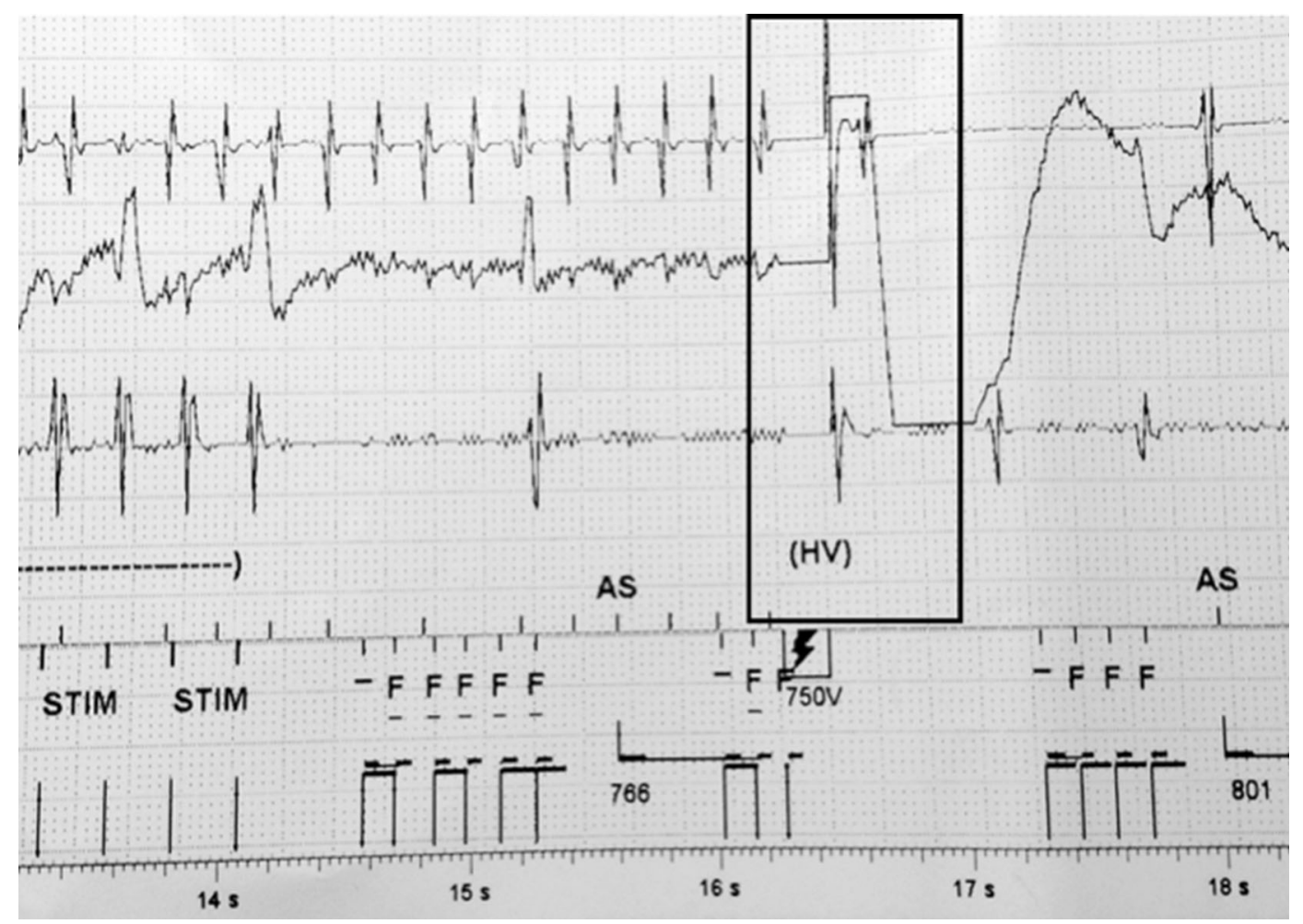

Fig. 2 Interrogation strip demonstrating device delivering anti-tachycardia pacing and shock therapy 

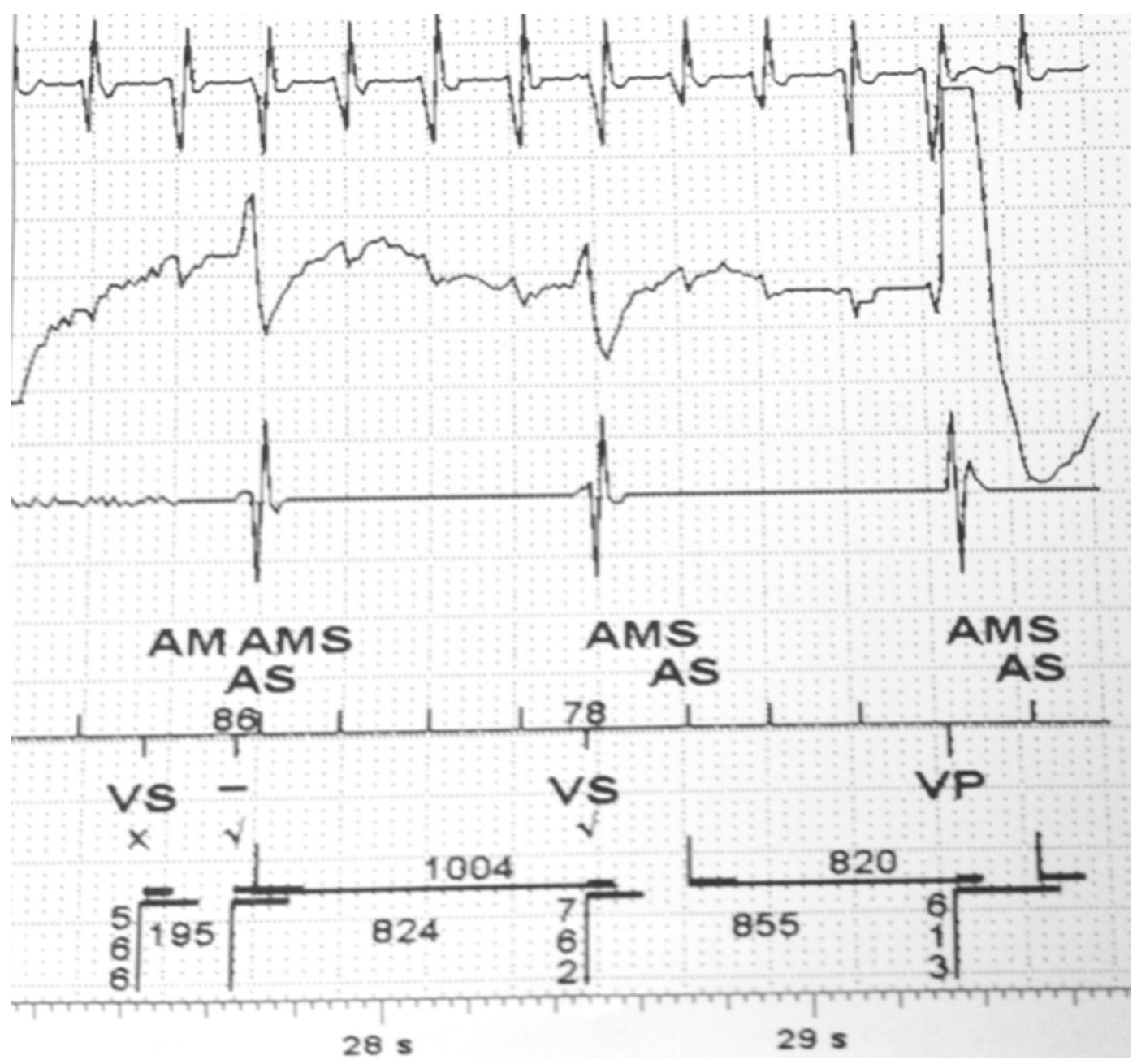

Fig. 3 External interference aborted upon stopping the chiropractic treatment

associated with an increase in cardiovascular and all-cause mortality [5, 6].

Reducing inappropriate therapy has been widely discussed. To maximize the effectiveness of ICDs and decrease the likelihood of inappropriate shocks, ICDs need to be programmed effectively by incorporating shorter programmed cycle lengths for VT selection intervals, anti-tachycardia pacing, lead fracture surveillance, as well as remote monitoring [3]. Innovations in ICD programming, including programming the device to only delivering a shock if the patient's heart rate is above 188, have been shown to be associated with a reduction in the rate of inappropriate discharge $[5,6]$. In addition, drug therapy has been shown to reduce the risk of inappropriate shock as well.
Beta-blockers slow the ventricular rate as well as atrial rate in medical conditions such as atrial fibrillation. This reduces the likelihood that sinus tachycardia, supraventricular tachycardia, or ventricular tachycardia will trigger the ICD to deliver an inappropriate shock. ICD programming and drug therapy together actually reduce mortality from inappropriate shock therapy by up to $50 \%[7,8]$. Rees and colleagues have reported that even a single inappropriate shock resulted in an increased risk of all-cause mortality [8]. Mortality risk increased with every subsequent shock [8].

In an ICD patient cohort, outside the setting of a clinical trial, inappropriate shocks may occur in up to $13 \%$ of ICD recipients [2]. Younger age, history of atrial fibrillation, and 
no statin use were all significant clinical predictors of inappropriate shocks. Of these associated clinical factors, a history of atrial fibrillation was the most significant baseline clinical predictor of inappropriate shock. Because inappropriate ICD discharges may occur spontaneously or due to a source in up $1 / 8$ of the ICD population, there is a need to educate patients in avoiding chiropractic treatments that utilize electrical muscle stimulation to relieve pain.

As described in a review of the literature involving physiotherapy and cardiac rhythm devices/ICDs, Digby et al. concludes that there are no specific guidelines regarding the administration of physiotherapy modalities such as TENS; however, recommendations from cardiac rhythm device and ICD manufacturers suggests that TENS therapy is best avoided in patients with cardiac rhythm devices or ICDs [9]. We agree with this recommendation. However, if TENS therapy is strongly indicated, either programming the device to avoid oversensing or temporarily turning it off could be considered under electrophysician supervision.

\section{ACKNOWLEDGEMENTS}

No funding or sponsorship was received for this study or publication of this article. All named authors meet the International Committee of Medical Journal Editors (ICMJE) criteria for authorship for this manuscript, take responsibility for the integrity of the work as a whole, and have given final approval for the version to be published.

Disclosures. Abhishek Shenoy, Abhishek Sharma, and Firehiwot Achamyeleh have nothing to disclose.

Compliance with Ethics Guidelines. Informed consent was obtained from the patient for being included in the study.

Open Access. This article is distributed under the terms of the Creative Commons
Attribution-NonCommercial 4.0 International License (http://creativecommons.org/licenses/ by-nc/4.0/), which permits any noncommercial use, distribution, and reproduction in any medium, provided you give appropriate credit to the original author(s) and the source, provide a link to the Creative Commons license, and indicate if changes were made.

\section{REFERENCES}

1. Occhetta E, Bortnik M, Magnani A, et al. Inappropriate implantable cardioverter-defibrillator discharge unrelated to supraventricular tachycardia. Europace. 2006;8:863-9.

2. Johannes B, Jan W, Mihaly $\mathrm{K}$, et al. Inappropriate implantable cardio-defibrillator shocks incidence, predictors and impact on mortality. JACC. 2011;57(5):556-62.

3. Koneru J, Swerdlow C, Wood M, et al. Minimizing inappropriate or "unnecessary" implantable cardioverter-defibrillator shocks appropriate programming. Circ: Arrhythm Electrophysiol. 2011;4:778-90.

4. Duan X. Electrocardiographic artifact due to a mobile phone mimicking ventricular tachycardia. J Electrocardiol. 2014;47(3):333-4.

5. Daubert JP, Zareba W, Cannom DS, et al. Inappropriate implantable cardioverter-defibrillator shocks in MADIT II: frequency, mechanisms, predictors, and survival impact. J Am Coll Cardiol. 2008;51:1357-65.

6. Raitt MH. Inappropriate implantable defibrillator shocks: an adverse outcome that can be prevented. J Am Coll Cardiol. 2013;62(15):1351-2.

7. Moss AJ, Schuger C, Beck CA, et al. Reduction in inappropriate therapy and mortality through ICD programming. N Engl J Med. 2012;367:2275-83.

8. Rees J. Inappropriate implantable cardioverter-defibrillator shocks. J Am Coll Cardiol. 2011;57(5):556-62.

9. Digby GC, Daubney ME, Baggs J, Campbell D, Simpson CS, Redfearn DP, Brennan FJ, Abdollah H, Baranchuk A. Physiotherapy and cardiac rhythm devices: a review of the current scope of practice. Europace. 2009;11(7):850-9. 